\title{
Credit Scoring with AHP and Fuzzy Comprehensive Evaluation Based on Behavioural Data from Weibo Platform
}

\author{
Jia YU, Jianrong YAO, Yuangao CHEN
}

\begin{abstract}
It is increasingly necessary to evaluate the customers' credit. In the era of big data, Information on the Internet is commonly used to judge the credit worthiness of customers. Some users' credit information is incomplete or unavailable, so credit managers cannot judge the true credit situation of these users. However, with the support of social data especially behavioural data and credit evaluation system, this problem can be effectively solved. This study used Weibo to obtain the behavioural data of Chinese users for credit evaluation. Two methods are used to calculate the credit scores of Weibo users, which are the analytic hierarchy process (AHP) and fuzzy comprehensive evaluation methods. By analysing social processes and inviting experts to make decisions, we constructed a credit evaluation system to expose users' behavioural characteristics. We found that the three key indexes determining the user's social credit are personal identification, behavioural characteristics and interaction among friends. Then, AHP was used to determine the weight of each index. Finally, a static algorithm was proposed to compute the credit evaluation system of Weibo users using fuzzy comprehensive evaluation methods.
\end{abstract}

Keywords: credit scoring; behavioural data; fuzzy comprehensive evaluation; social media platform; Weibo

\section{INTRODUCTION}

Credit scoring is a necessary finance activity. In recent years, personal credit scoring is more and more important in the commercial field. Credit scoring aims to divide users into two categories: users with good credit and users with bad credit $[1,3]$. Credit scores are mostly determined by the probability of loan default [2]. Before granting a loan, evaluating the applicant's credit can reduce the business risk of the enterprise. With the development of E-commerce and Internet Finance, the importance of personal credit evaluation is increasing. Credit scoring models and classifier systems are also constantly improved [3].

Forecasting the customer's default probability needs data support, and a different enterprise has various data source. Most banks have their own internal database. They will use the basic information of customers to evaluate the credit, such as the previous borrowing, loan payments, age, residence and work unit [4]. Some small-medium-sized enterprises have limitations in ability and cost, they will turn to the third-party business credit institutions for assistance. Wireless Telecommunication Company can provide SMEs with customer's identity information, call records and payment orders [5]. The traditional Peer-toPeer (P2P) lending market uses a variety of financial data to build credit scoring systems. Other enterprises will evaluate their customers' credit according to the purchase record and purchase evaluation, or directly using the credit scoring system on the E-commerce platform to obtain credit value [6]. However, there are deficiencies in credit scoring when using the data mentioned above. The customers' information in banks or other financial institutions is updated slowly, and the call records or bills can be falsified to confuse the relevant enterprise. Moreover, state-of-theart credit scoring system cannot meet the huge demand of the usable credit evaluation in P2P lending market [7]. And sometimes we cannot distinguish real transactions and false transactions on the E-commerce platform. Thus, the existing credit scoring system is still inadequate. The accuracy of credit scoring is determined by the type of data and the amount of data. Behavioural data, as the data that cannot be ignored, is being used more and more for credit scoring. And behavioural data is most useful for users who have no credit history.

In recent years, the financing needs of individuals and enterprises have promoted the development of online P2P lending market, such as "RenrenDai" in China. These platforms broaden the borrower's borrowing channels, but at the same time, how to evaluate the borrower's credit is particularly important. In addition to investigating the borrower's registered personal information, they will take the borrower's behavioural data on the platform as a reference, such as loan application, forum level, comments, membership scores and group [8]. A person's behavioural data can reveal his behavioural characteristics and can be used as part of credit data to evaluate credit. For instance, "Zhima credit" is the third-party credit agency under the "Ant financial", which objectively presents the user's credit by cloud computing, machine learning and other technologies. Chinese consumers are accustomed to using Alipay to pay instead of cash and functions in Alipay are abundant, so Alipay is covered with users' behaviour footprints. Similar to using the FICO score to get the personal credit score [9], "Zhima credit" announces the user's credit score through these behavioural footprints. The behavioural data involved in the scoring process are as follows: repayment behaviour, shopping, credit transfer, financial management, interaction between friends and so on.

Today our daily life is inseparable from some social platform and almost everyone will comment on something, like, forward related blogs and tweets, or follow some top celebrities and masters [10]. So much useful information can be obtained, especially the information related to the behaviour of users. Social platform can bring people a lot of convenience, however, the false information and a variety of fraud issues have been transmitted in a high speed at the same time. There are some cheats or people who spread false information on the social platform, so we should find the right way to judge users with good credit and users with bad credit $[1,11]$. By analyzing the huge behavioural data on the social platform, we can achieve diverse purposes including evaluating personal credit of users in Social Network Sites (SNS) [12]. 
There are a variety of social platforms, such as Twitter, Facebook, Myspace and Weibo, in which a large number of social messages and users' information can be mined. According to the financial report officially published on the Weibo platform in 2017 (https:/www.weibo.com/), as of March 31, 2017, Weibo's monthly active users had exceeded Twitter by 340 million. As of September 2017, monthly active users on Weibo had reached 376 million, and the platform was continuing to maintain steady growth. Therefore, we chose Weibo as the data source for this paper. Some of the user's daily consumer activities or financial activities will be reflected on SNS, therefore, the relevant financial institutions can utilize the user's information on the social platform to assess the user's credit, which must make good use of behavioural data. In general, the more complete the user's data, the higher his credibility will be. On social platform, part of the user's information is identity authentication data, such as date of birth, gender, ID, educational background and blood type. But more is the user's behavioural data, such as sports data, consumer sharing, comments, forwarding, and the number of followers. Although most of the data are unstructured and shambolic, these data allow us to gain a deeper understanding of users, especially their preferences and personalities [13]. In the absence of users' credit history, we can evaluate their credit through their behavioural data. Credit is essentially generated by behaviour, and behavioural data can validate a person's credit in the other way round. Therefore, it is necessary to use appropriate tools or methods to obtain and analyze these data, and to find out the relationship between personal credit and these data.

This paper focuses on analyzing the credit of users through Weibo data and seeking the factors for user's credit evaluation. Then we summarize the key elements of the user's behaviour and determine the weight of each evaluation factor when using the Weibo. Lastly, we propose a static algorithm for user credit evaluation. The article tries to use Analytic hierarchy process (AHP) and fuzzy comprehensive evaluation method to evaluate credit according to user's behavioural data. Before all the work, digging out the data that we need is a necessary step. In the course of our research, we construct the index structure of the credit evaluation system for users and refine the three main elements that affect the credit of Weibo users, respectively, personal identification, behavioural characteristics and interaction among friends.

The study of using Weibo social data, especially behavioural data, to evaluate the user's credit is rare. So the innovation of this paper is that we adopt the behavioural data on Weibo of users to evaluate their credit, not to mention that we have proposed this paper's unique credit evaluation index systems.

The rest of the paper is organized as follows. In Section 2 , we review the relevant literature on credit scoring methods and relevant researches on the use of behavioural data. In Section 3, the acquisition and processing of the data are introduced, we list the important factors which will influence the credit score and draw the credit evaluation index system. In Section 4, we randomly select a Weibo user for empirical analysis and evaluate the user's credit by using AHP and fuzzy comprehensive evaluation method. Based on the preliminary works and forecast results,
Section 5 draws conclusions and future research directions.

\section{LITERATURE REVIEW}

Credit scoring has become a very significant task due to the rapid development of the credit industry [14]. Many scholars are trying to establish an efficient, transparent and unbiased credit rating system, so that the Internet financial enterprises can assess the customer's credit situation better [15]. In order to optimize the credit decision and enhance the competitiveness of enterprises, it is necessary to apply new technologies and efficient data mining tools to optimize the credit scoring model [16]. The E-commence platform and P2P lending platform are different from the traditional bank or ordinary businesses, which is a virtual platform for business activities based on the Internet. Therefore, the evaluation of the user's credit on these platforms is not only limited to the user's personal information, but also takes behavioural data into account, such as publishing evaluation, releasing borrowing requirements. And the credit scoring methods should be more appropriate.

Plenty of previous works discussed the credit scoring method. Credit scoring methods can be generalized into two categories: statistical techniques and artificial intelligence methods $[1,17,18]$. Artificial Neural Networks (ANNs) is becoming more popular in the field of credit scoring because of its related memory characteristics and generalization ability $[19,20]$. Chih-Fong Tsai and Chihli Hung [21] not only used neural network to evaluate the credit, but also concluded that the prediction of a hybrid neural network was more accurate than a single neural network, which was tested on Australia, Germany and Japan databases. In addition, Support Vector Machine (SVM) is also a method of credit evaluation. Tony Bellotti and Jonathan Crook [22] tested the credit data in their works and found that the SVM was more successful in establishing the credit default classification method. Siami M. and Gholamian M. R. et al. [23] proposed the locally linear model tree algorithm to evaluate customer's credit, and tested the accuracy of the predictions on the Australia and Germany credit data sets. With the development of technology, researchers are inclined to use hybrid methods. Gang Wang and Jian Mac [24] proposed a new hybrid ensemble approach RSB-SVM in order to assess enterprise's credit risk, which is based on two popular ensemble strategies, i.e., bagging and random subspace, and used SVM as base learner in their paper. In addition, Mirta Bensic and Natasa Sarlija et al. [25] compared the accuracy of logical regression, neural networks, and CART decision trees in evaluating credit, and tested four different neural network algorithms with a small dataset in order to obtain the credit characteristics. According to Yung-Chia Chang and Kuei-Hu Chang [26], the recall rate and precision of the credit classification model they proposed was significantly better than Logistic regression and Cox proportional hazards models. More recently, Bach M. P. and Zoroja J. et al. [27] selected the appropriate variables to evaluate the borrower's credit risk and obtained the classification accuracy of the decision tree model based on these variables As a benchmark, different algorithms which selected different variables were evaluated.

Most of the statistical techniques or artificial 
intelligence methods mentioned above are accustomed to dividing the subjects into two categories, namely, good credit and bad credit. The results of credit scoring can also be expressed by specific credit figures [28]. This process commonly involves adding tag to users and setting weight to variables. Ahmad Nadali and Sanaz Pourdarab [29] took the Bank of Iran as a demonstration and introduced analytic hierarchy process and SAW methods before implementing data mining algorithms, finally got the credit score of the bank customers and their corresponding credit level. Ferreira F A F and Santos S P et al. [30] applied the AHP in proposing a framework for the evaluation of the mortgage risk to evaluate the credit risk of the user's mortgage, and used the credit score to help the bank make the decision. Due to the existence of analytic hierarchy process, Chowdhury S and Roy B C [31] developed a fuzzy analytic hierarchy process based on the views of various experts in the banking and microfinance fields as well as the real-time data collected from the MIX market, and then obtained the credit score of the microfinance institutions. Yan Li [32] proposed an improved fuzzy comprehensive evaluation method to perform credit evaluation more effectively, and described the specific operation of customer credit scoring based on the analysis of the status of financial institutions. Moreover, many scholars have made a comprehensive research on credit scoring. Hooman A, Marthandan G et al. [33] described in detail the various data mining methods and statistical methods in the credit scoring process so that researchers could find the best way to evaluate credit, identify the limitations of them and improve. It is necessary to draw a detailed evaluation index system before evaluating a person's credit.

In recent years, the potential customers of enterprises are increasing with the increase of network services under the Internet environment, so personal credit scoring is becoming more and more important. However, existing credit scoring methods based on financial data or personal information are faced with severe challenges when dealing with heterogeneous social data [34]. Behavioural data is gradually applied to personal credit assessment to serve as an evaluation reference for people who have no credit record. A lot of researches used user behaviour data on the $\mathrm{P} 2 \mathrm{P}$ lending website to predict their default rate $[8,35]$, and studies had shown that social relationships also affected the success rate of borrowing [36]. In the context of growing social media, MA Ahmad and J Srivastava tried to tap user's behavioural data in massive online games from social science perspectives, thereby conducted social analysis [37]. Most of behavioural data depends on the social media and the impact of various media on our lives is growing. Social media will influence individual investment decisions. Yang Y, Gu J et al. [38] chose the two most representative social platforms in Chinese financial area and selected behavioural data to do textual analysis, which proved that the results of credit risk prediction using behavioural data were more accurate than those predicted by professional risk managers. Behavioural data is applied not only in personal credit scoring, but also in other research areas. Lee $\mathrm{R}$, Wakamiya S et al. [39] collected behavioural data of registered users from Twitter and then summarized their behaviour patterns to describe the characteristics of urban areas, finally proposed a model to test the relationship between users and areas. Yue K, Wu H et al. [40] found out the similarity of users on the social media from a large number of social behaviours, and proposed a new method to discover user similarities based on Bayesian Networks (BN). Besides, Harari G. M., Lane N. D. et al. [41] collected daily behavioural data from smartphones to apply them to Psychology. Human behaviour is a manifestation of living habits, from the behavioural data can get the most authentic research results.

According to the above introduction, we can know that behavioural data can reflect a person's character and traits. Therefore, we choose the behavioural data from Weibo as the research data of this paper. In the face of the large and complex Weibo behavioural data, this paper tries to choose a common and understandable method, namely AHP and fuzzy comprehensive evaluation method. In addition, we construct a credit evaluation index system very carefully which is different from other scholars. The main concern of this article is personal credit, which can be evaluated by his behavioural data on Weibo when the user has no credit history or details. Moreover, the evaluation of user credit is expressed by an exact numerical value.

\section{CREDIT EVALUATION INDEX SYSTEM FOR WEIBO USER}

\subsection{Data Mining}

The data used in this paper are all kinds of information of the users on Weibo and these data come from the blog content or personal information content that the user publishes on Weibo. The corresponding data mining tools and techniques are needed to mine the data. Python is the main tool to mine the data from Weibo.

There are many kinds of data to be excavated on the Weibo platform, such as text, pictures, audio and video, etc. In these data, there is a clear digital data, but also a strong subjective personal point of view. After digging out the data we want, there is the question of how qualitative indicators quantify. This is a particularly important step in quantifying qualitative indicators and making them conform to the actual situation, which will be described in the following sections. The combination of quantitative analysis and qualitative assessment to analyse the individual credit status of users can make more accurate and comprehensive evaluation. The volume of Weibo data is so large that the operation of data pre-processing is required after the data is mined. Data pre-processing includes data cleaning, data integration and data normalization. For instance, classify each user's data according to the classification framework of this article, and classify the account information such as age, region and places of work into account registration information as mentioned above. In order to ensure the normalization and correctness of the calculation process, we predict the most probable values or delete the vacancy values, clear the exception values and duplicate values, etc.

Based on the previous credit scoring model $[7,8]$ and the data we collected from Weibo, we generalize these data into three variable sets: basic information, social information and activity information. In Tab. 1, we list the variables and their description.

In these three major behavioural aspects, we can get a lot of reliable data. For example, basic information includes users' ID, the user's gender, birthday and other personal identity information. Generally, online activity refers to the 
state of users after they $\log$ in, such as he is active or he is silent, which is an indicator to track users' behaviour. At the same time, the activity information also reflects the user's daily activities. In addition, the most important data in this paper is the social information on the Weibo, such as tweeting, commenting on other tweets, forwarding and favourites, etc.

\begin{tabular}{|c|c|c|}
\hline Variable sets & Variable & Value and description \\
\hline \multirow[t]{6}{*}{$\begin{array}{l}\text { Basic } \\
\text { information }\end{array}$} & ID & $\begin{array}{l}0: \text { chaotic } \\
\text { 1: regular }\end{array}$ \\
\hline & Age & $\begin{array}{l}0: \text { no introduction } \\
1: \text { under } 20 \text { years old } \\
2: 21-30 \text { years old } \\
3: 31-40 \text { years old } \\
4: 41-50 \text { years old } \\
5: \text { over } 51 \text { years old } \\
\end{array}$ \\
\hline & Sex & $\begin{array}{l}0: \text { female } \\
1: \text { male }\end{array}$ \\
\hline & Location & $\begin{array}{l}\text { 0: no introduction } \\
\text { 1: Descriptive detailed }\end{array}$ \\
\hline & Contact way & $\begin{array}{l}0: \text { no introduction } \\
\text { 1: Descriptive detailed }\end{array}$ \\
\hline & Work & $\begin{array}{l}\text { 0: no introduction } \\
\text { 1: Descriptive detailed }\end{array}$ \\
\hline \multirow[t]{5}{*}{$\begin{array}{l}\text { Social } \\
\text { information }\end{array}$} & Following & $\begin{array}{l}\text { The number of following in }[0 \text {, } \\
3000]\end{array}$ \\
\hline & Followers & $\begin{array}{l}\text { The number of followers in }[0 \text {, } \\
900000000]\end{array}$ \\
\hline & Updates & $\begin{array}{l}\text { The number of updates in }[0 \text {, } \\
100000]\end{array}$ \\
\hline & Favourites & $\begin{array}{l}\text { The number of updates in }[0 \text {, } \\
100000]\end{array}$ \\
\hline & Interaction & $\begin{array}{l}0: \text { No interaction } \\
\text { 1: interact frequently }\end{array}$ \\
\hline \multirow[t]{3}{*}{$\begin{array}{l}\text { Activity } \\
\text { information }\end{array}$} & Athletic records & $\begin{array}{l}\text { 0: no introduction } \\
\text { 1: Descriptive detailed }\end{array}$ \\
\hline & $\begin{array}{l}\text { Online purchase } \\
\text { history }\end{array}$ & $\begin{array}{l}\text { 0: no introduction } \\
\text { 1: Descriptive detailed }\end{array}$ \\
\hline & Entertainments & $\begin{array}{l}\text { 0: no introduction } \\
\text { 1: Descriptive detailed }\end{array}$ \\
\hline
\end{tabular}

\subsection{Personal Credit Evaluation Index System}

The credit of Weibo users is calculated through the user's social data especially behavioural data, reflecting the user's information authenticity, activities and behavioural habits on the social platform. According to the characteristics of Weibo, we screen the three behavioural aspects, so that the factors that influence the user's credit are closely related to Weibo. For instance, those athletic data and purchase records which can be obtained in equipment or other shopping sites have little correlation with Weibo, so we abandon the data like this in our study.

In this study, we mainly use the process analysis method to identify the elements for individual credit evaluation. According to the process analysis method, we will observe the whole process and steps of the user's activity on Weibo, analyze the internal logical relation, and draw the flow chart. Detailed segmentation of each step is carried out. We investigate each step so as to identify the specific factors that influence the personal credit of the users. Finally, this paper constructs the personal credit evaluation index system of Weibo users by combining the characteristics of Chinese netizen and inviting relevant experts to weigh the importance of indexes.

Through the analysis of user behaviour we can conveniently design the credit index system of Weibo users, and by selecting the key elements of the behaviour of the users in the use of Weibo, we summarize the relevant elements of the credit evaluation. In this paper, the index system is divided into three layers. First, we determine the three dimensions of the highest layer, namely, personal identification, behaviour analysis and interaction among friends, and then extend the secondary index layer and the third layer. Indexes of each indicator layer are associated with the user's credit, thus indicating the rationality and feasibility of the evaluation method. Tab. 2 is a detailed credit evaluation index system for Weibo user constructed in this paper.

Table 2 Credit evaluation index system for Weibo user

\begin{tabular}{|c|c|c|}
\hline The First Layer & $\begin{array}{l}\text { The Secondary } \\
\text { Layer }\end{array}$ & The Third Layer \\
\hline \multirow{4}{*}{$\begin{array}{l}\text { A Identification } \\
\text { of Individuals }\end{array}$} & \multirow{2}{*}{$\begin{array}{l}\text { A1 Completeness } \\
\text { of Information }\end{array}$} & A11 Basic Information Integrity \\
\hline & & A12 Certification Status \\
\hline & \multirow{2}{*}{$\begin{array}{l}\text { A2 Registration } \\
\text { Status }\end{array}$} & A21 Registration Time \\
\hline & & A22 Registration Id \\
\hline \multirow{11}{*}{$\begin{array}{l}\text { B } \\
\text { Behaviour } \\
\text { Analysis }\end{array}$} & \multirow{3}{*}{$\begin{array}{l}\text { B1 } \\
\text { Online Situation }\end{array}$} & $\begin{array}{l}\text { B11 Degree of Activity Within A } \\
\text { Month }\end{array}$ \\
\hline & & B12 Last Login Time \\
\hline & & B13 Degreeof Overall Activity \\
\hline & \multirow{2}{*}{$\begin{array}{l}\text { B2 Release } \\
\text { Situation }\end{array}$} & B21 Number of Tweets \\
\hline & & B22 Content of Tweets \\
\hline & \multirow{2}{*}{$\begin{array}{l}\text { B3 Forwarding } \\
\text { Situation }\end{array}$} & $\begin{array}{l}\text { B31 Number of The Forwarding } \\
\text { Tweets }\end{array}$ \\
\hline & & $\begin{array}{l}\text { B32 Content of The Forwarding } \\
\text { Tweets }\end{array}$ \\
\hline & \multirow{2}{*}{$\begin{array}{l}\text { B4 Comment } \\
\text { Situation }\end{array}$} & B41 Number of Comments \\
\hline & & B42 Content of Comments \\
\hline & \multirow{2}{*}{$\begin{array}{l}\text { B5 Other } \\
\text { Situations }\end{array}$} & B51 Level of Account \\
\hline & & B52 Medal / Designation \\
\hline \multirow{6}{*}{$\begin{array}{l}\mathrm{C} \\
\text { Interaction } \\
\text { among Friends }\end{array}$} & \multirow{3}{*}{$\begin{array}{l}\text { C1 Friend } \\
\text { Relations }\end{array}$} & C11 Number of Followers \\
\hline & & C12 Number of Following \\
\hline & & C13 The Rank of Friends \\
\hline & \multirow{3}{*}{$\begin{array}{l}\text { C2 Group } \\
\text { Relations }\end{array}$} & C21 Number of Groups \\
\hline & & C22 Number of Group Members \\
\hline & & $\begin{array}{l}\text { C23 The Rank of a Group } \\
\text { Member }\end{array}$ \\
\hline
\end{tabular}

\section{EMPIRICAL ANALYSIS BASED ON BEHAVIOURAL DATA}

We randomly sampled 100 users from Weibo as research samples. We used behavioural data of these 100 users to validate the method proposed in this paper, and proved the feasibility and rationality of using behavioural data to evaluate credit of users. Since the length of the article is limited and each user's evaluation process is similar, we randomly selected a user named "FreshBoy" as a case and then calculated his credit score and evaluated it.

\subsection{Adopting AHP to Determine Weight of Parameters}

Analytic hierarchy process (AHP) is a multi-objective and multi-criteria decision analysis method proposed in 1970s by T. L. Saaty, an American research expert. AHP is a combination of quantitative and qualitative methods to express and deal with the subjective judgments of human beings in the form of quantity. And it can also prompt people to judge whether there is contradiction between the subjective judgments of a problem, which is an effective way to describe a person's subjective judgment objectively. Using AHP, we can divide each factor of a complex problem into several interrelated order layers, then 
combine the expert opinion and the analyst's objective judgment result effectively by comparison, and determine the local priority weight of each factor in each layer. At last, a mathematical method is used to calculate the weights that reflect the relative importance order of each layer element, and the relative weights of all the elements are computed and sorted by the total ordering among all the layers.

In Section 3 of this article, we constructed the credit evaluation index system of Weibo users, and each layer of the corresponding index had been listed in detail. This paper uses AHP to determine the importance of the indexes in lower layer to that of the indexes in upper layer, so that we can easily calculate the score of indexes in the upper layer by fuzzy comprehensive evaluation method. The following content is the calculation process of the weights of indexes, including constructing judgment matrix, calculating the weight values and testing the consistency, in which the calculation results are obtained by MATLAB software.

In Tab. 3 , both $W$ and $\lambda_{\max }$ are calculated from matrix operations. CI represents consistency indicators. The smaller the $C I$, the greater the consistency. The formula of $C I$ is as follows, where $n$ is the order of the matrix.

$C I=\frac{\lambda-n}{n-1}$

When we test whether the judgment matrix has satisfactory consistency, we also need to compare $C I$ with $R I$, and get the check coefficient $C R$. The values of $R I$ of matrices with different orders are fixed.

$C R=\frac{C I}{R I}$

Generally, the judgment matrix is considered to pass the consistency test when $C R<0.1$.

Table 3 The calculation results of the weights of the indexes

\begin{tabular}{|l|c|c|c|}
\hline \multicolumn{1}{|c|}{$W$} & $\lambda_{\max }$ & $C I$ & $C R$ \\
\hline$W_{0}=W_{\mathrm{A}, \mathrm{B}, \mathrm{C}}=[0.1692,0.4439,0.3869]$ & 3.0192 & 0.0096 & 0.0166 \\
\hline$W_{\mathrm{A}}=W_{\mathrm{A} 1, \mathrm{~A} 2}=[0.5,0.5]$ & 2 & 0 & 0 \\
\hline $\begin{array}{l}W_{\mathrm{B}}=W_{\mathrm{B} 1, \mathrm{~B} 2 \mathrm{~B} 3, \mathrm{~B} 4, \mathrm{~B} 5}= \\
=[0.0502,0.0812,0.1644,0.1868,0.5175]\end{array}$ & 5.2729 & 0.0682 & 0.0609 \\
\hline$W_{\mathrm{C}}=W_{\mathrm{C} 1, \mathrm{C} 2}=[0.2,0.8]$ & 2 & 0 & 0 \\
\hline$W_{\mathrm{A} 1}=W_{\mathrm{A} 11, \mathrm{~A} 12}=[0.3333,0.6667]$ & 2 & 0 & 0 \\
\hline$W_{\mathrm{A} 2}=W_{\mathrm{A} 21, \mathrm{~A} 22}=[0.8571,0.1429]$ & 2 & 0 & 0 \\
\hline $\begin{array}{l}W_{\mathrm{B} 1}=W_{\mathrm{B} 11, \mathrm{~B} 12, \mathrm{~B} 13}= \\
=[0.1692,0.4439,0.3869]\end{array}$ & 3.0192 & 0.0096 & 0.0166 \\
\hline$W_{\mathrm{B} 2}=W_{\mathrm{B} 21, \mathrm{~B} 22}=[0.8571,0.1429]$ & 2 & 0 & 0 \\
\hline$W_{\mathrm{B} 3}=W_{\mathrm{B} 31, \mathrm{~B} 32}=[0.8571,0.1429]$ & 2 & 0 & 0 \\
\hline$W_{\mathrm{B} 4}=W_{\mathrm{B} 41, \mathrm{~B} 42}=[0.5,0.5]$ & 2 & 0 & 0 \\
\hline$W_{\mathrm{B} 5}=W_{\mathrm{B} 51, \mathrm{~B} 52}=[0.3333,0.6667]$ & 0 & 0 \\
\hline $\begin{array}{l}W_{\mathrm{C} 1}=W_{\mathrm{C} 11, \mathrm{C} 12, \mathrm{C} 13}= \\
=[0.1007,0.2255,0.6738]\end{array}$ & 3.0858 & 0.0429 & 0.0739 \\
\hline $\begin{array}{l}W_{\mathrm{C} 2}=W_{\mathrm{C} 21, \mathrm{C} 22, \mathrm{C} 23}= \\
=[0.1007,0.2255,0.6738]\end{array}$ & 3.0858 & 0.0429 & 0.0739 \\
\hline
\end{tabular}

- The following is the judgement matrix and the corresponding weight calculation results obtained by comparing $A, B$ and $C$ :

$$
\boldsymbol{R}_{1}=\left[\begin{array}{ccc}
1 & 1 / 3 & 1 / 2 \\
3 & 1 & 1 \\
2 & 1 & 1
\end{array}\right]
$$

$W_{0}=[0.1692,0.4439,0.3869]$,

$C I=0.0096, R I=0.58, C R=0.0166<0.1$.

The result of the calculation shows that the weight of indexes $A, B, C$ is set reasonably.

The set and verification process of weight of indexes is similar, so this section omits the related operation of the remaining indexes. Meanwhile, the computational process is cumbersome, so we do not specifically list the calculation process but directly use the tool to get the corresponding results. Tab. 3 shows the index weights of each layer. As shown in Tab.3, the $C R$ of each weight is less than 0.1 , which indicates that the consistency of the judgment matrix is good and the weight $W$ is acceptable.

\subsection{The Fuzzy Comprehensive Evaluation of Weibo Users' Credit}

\subsubsection{Establishing a Set of Grade for Credit Scoring}

The object of this paper is the credit of Weibo users. In order to differentiate conveniently, we divide the credit into five grades, which are very good, good, general, poor and very poor. Each grade corresponds to a different value interval, and the middle value is used as the quantization value of the grade. Tab. 4 shows the quantization table of grade for credit scoring. We can get the parameter vector: $\boldsymbol{L}$ $=\left[\begin{array}{lllll}90 & 70 & 30 & 10\end{array}\right]$.

Table 4 Quantization table of grade for credit scoring

\begin{tabular}{|c|c|c|c|}
\hline $\begin{array}{c}\text { Evaluation } \\
\text { grade }\end{array}$ & $\begin{array}{c}\text { Content of } \\
\text { evaluation grade }\end{array}$ & $\begin{array}{c}\text { Value } \\
\text { interval }\end{array}$ & $\begin{array}{c}\text { Quantization value } \\
\text { of the grade }\end{array}$ \\
\hline 1 & Very good & $(80,100]$ & 90 \\
2 & Good & $(60,80]$ & 70 \\
3 & General & $(40,60]$ & 50 \\
4 & Poor & $(20,40]$ & 30 \\
5 & Very poor & {$[0,20]$} & 10 \\
\hline
\end{tabular}

\subsubsection{Determining the Membership Functions}

In this paper, we choose a simple trapezoid membership function in order to calculate more easily. The following equations we have listed are the membership functions. The closer the membership degree $f(x)$ is to 1 , the higher the degree that $x$ belongs to $f$. After getting the score of the credit evaluation index of Weibo users, we can get the grade for credit of each index according to the membership function. As shown in Eq. (9), we derive the score for each index in the credit evaluation system in Tab. 5 , which is substituted into the Eqs. (4) - (8) as the $x$.

$f_{1}(x)=\left\{\begin{array}{cc}0, & x \leq 70 \\ (x-70) / 20, & 70<x \leq 90 \\ 1, & 90<x \\ 0, & x \leq 50\end{array}\right.$

$f_{2}(x)=\left\{\begin{array}{cc}0, & x \leq 50 \\ (x-50) / 15, & 50<x \leq 65 \\ 1, & 65<x \leq 75 \\ (90-x) / 15, & 75<x \leq 90 \\ 0, & 90<x\end{array}\right.$

$\lambda_{\max }=3.0192$, 


$$
\begin{aligned}
& f_{3}(x)=\left\{\begin{array}{cc}
0, & x \leq 30 \\
(x-30) / 15, & 30<x \leq 45 \\
1, & 45<x \leq 55 \\
(70-x) / 15, & 55<x \leq 70 \\
0, & 70<x
\end{array}\right. \\
& f_{4}(x)=\left\{\begin{array}{cc}
0, & x \leq 10 \\
(x-10) / 15, & 10<x \leq 25 \\
1, & 25<x \leq 35 \\
(50-x) / 15, & 35<x \leq 50 \\
0, & 50<x
\end{array}\right. \\
& f_{5}(x)=\left\{\begin{array}{cc}
1, & x \leq 10 \\
(30-x) / 20, & 10<x \leq 30 \\
0, & 30<x
\end{array}\right.
\end{aligned}
$$

\subsubsection{Calculating Indexes}

The credit evaluation of Weibo users is vague and subjective, and the number of Weibo users is large and the content is very rich. In order to solve these problems, we use the function and scientific scoring criteria to calculate the index.

For qualitative indicators, it is difficult to measure without explicit data and standards. Therefore, this paper gathers experts in this field to establish scoring rules. For example, in terms of the index item A22, if a user's registered ID has obvious traces of life, it scores 80; if the registered ID is composed of unordered letters or numbers, it scores 20. And for the index item B32, the original score we set for the index is 100 . If there is any spam or illegal content in the forwarding tweets, 10 points will be deducted. For the quantitative index, although the exact value can be directly obtained, there is a big difference between the original data of each index, and it cannot be directly used for evaluation calculation. So we must also convert it to the same standard score. For the index item B12, what we get directly from the data is a clear date when the user last logged in. However, if we want to know how long the user logged last time, in other words, the last login time, we can select a piece-wise function.

$S=\left\{\begin{array}{cc}100-\frac{100}{365} x & x \in[0,365] \\ 0 & x>365\end{array}\right.$

Referring to the credit evaluation index system given in this paper, and combining the calculation method of the index mentioned above, the scores of each index are calculated. After calculating the score of each index, we can know the corresponding evaluation interval and evaluation set of this value. Each grade has its own membership function. We can get the membership degree of the evaluation grade by substituting the index score into each membership function. Tab. 5 is the scoring result of the Weibo user "FreshBoy", which is a very important step to judge the user's credit with the fuzzy comprehensive

\begin{tabular}{|c|c|c|c|c|c|c|}
\hline \multirow{2}{*}{ Index } & \multirow{2}{*}{ Score } & \multicolumn{5}{|c|}{ Membership degree of evaluation grade } \\
\hline & & 1 Very good & 2 Good & 3 General & 4 Poor & 5 Very poor \\
\hline A11 Basic information integrity & 90 & 1 & 0 & 0 & 0 & 0 \\
\hline A12 Certification status & 50 & 0 & 0 & 1 & 0 & 0 \\
\hline A21 Registration time & 100 & 1 & 0 & 0 & 0 & 0 \\
\hline A22 Registration ID & 80 & 0.5 & 0.67 & 0 & 0 & 0 \\
\hline B11 Degree of activity within a month & 88 & 0.9 & 0.13 & 0 & 0 & 0 \\
\hline B12 Last login time & 70 & 0 & 1 & 0 & 0 & 0 \\
\hline B13 Degree of overall activity & 73 & 0.15 & 1 & 0 & 0 & 0 \\
\hline B21 Number of tweets & 86 & 0.8 & 0.27 & 0 & 0 & 0 \\
\hline B22 Content of tweets & 100 & 1 & 0 & 0 & 0 & 0 \\
\hline B31 Number of the forwarding tweets & 20 & 0 & 0 & 0 & 0.67 & 0.5 \\
\hline B32 Content of the forwarding tweets & 64 & 0 & 0.93 & 0.4 & 0 & 0 \\
\hline B41 Number of comments & 50 & 0 & 0 & 1 & 0 & 0 \\
\hline B42 Content of comments & 88 & 0.9 & 0.13 & 0 & 0 & 0 \\
\hline B51 Level of account & 92 & 1 & 0 & 0 & 0 & 0 \\
\hline B52 Medal / Designation & 35 & 0 & 0 & 0 & 1 & 0 \\
\hline C11 Number of followers & 96 & 1 & 0 & 0 & 0 & 0 \\
\hline C12 Number of following & 75 & 0.25 & 1 & 0 & 0 & 0 \\
\hline C13 The rank of friends & 78 & 0.4 & 0.8 & 0 & 0 & 0 \\
\hline C21 Number of groups & 0 & 0 & 0 & 0 & 0 & 1 \\
\hline C22 Number of group members & 0 & 0 & 0 & 0 & 0 & 1 \\
\hline C23 The rank of a group member & 0 & 0 & 0 & 0 & 0 & 1 \\
\hline
\end{tabular}
evaluation method.

Table 5 The scoring result of FreshBoy

\subsubsection{Credit Scoring by Fuzzy Comprehensive Evaluation}

According to Tab. 5, we can intuitively get the fuzzy relation matrix of the secondary indexes. For example, the fuzzy relation matrix of $\boldsymbol{A} 1$ is

$\boldsymbol{R} \boldsymbol{A} 1=\left[\begin{array}{lllll}1 & 0 & 0 & 0 & 0 \\ 0 & 0 & 1 & 0 & 0\end{array}\right]$
And the corresponding weight vector is $\boldsymbol{W}_{\mathrm{Al}}=[0.3333$, 0.6667]. Therefore, the fuzzy evaluation vector of $\boldsymbol{A} 1$ is calculated as

$$
\boldsymbol{E} \boldsymbol{A} 1=\boldsymbol{W} \boldsymbol{A} 1 * \boldsymbol{R} \boldsymbol{A} 1=\left[\begin{array}{lllll}
0.3333 & 0 & 0.6667 & 0 & 0
\end{array}\right]
$$

Similarly, we can get the other fuzzy evaluation vectors. According to the calculation results, we use the 
fuzzy transformation results of the above indicators to carry out a comprehensive evaluation for the indicators in the first layer.

$$
\begin{aligned}
& \boldsymbol{E} \boldsymbol{A}=\boldsymbol{W} \boldsymbol{A} * \boldsymbol{R} \boldsymbol{A}=\boldsymbol{W} \boldsymbol{A} *\left[\begin{array}{l}
\boldsymbol{E} \boldsymbol{A} 1 \\
\boldsymbol{E} \boldsymbol{A} 2
\end{array}\right]= \\
& =\left[\begin{array}{lllll}
0.6310 & 0.0479 & 0.3334 & 0 & 0
\end{array}\right]
\end{aligned}
$$

$$
E 0=W 0 * R 0=W 0 *\left[\begin{array}{c}
E A \\
E B \\
E C
\end{array}\right]=
$$

$=\left[\begin{array}{lllll}0.2882 & 0.1097 & 0.0610 & 0.1950 & 0.3408\end{array}\right]$

In accordance with the principle of maximum membership, the user's credit rating is "very poor", indicating that the user's credibility is very low. The content he released is not reliable. In order to obtain the user's specific credit score, we will take $E_{0}$ to the normalization.

$$
\boldsymbol{E} 0^{\prime}=\left[\begin{array}{lllll}
0.2897 & 0.1103 & 0.0613 & 0.1960 & 0.3426
\end{array}\right]
$$

The normalized $\boldsymbol{W}$ is multiplied by the parameter vector $\boldsymbol{L}$ to obtain the overall credit score of the user:

$$
\boldsymbol{S}=\boldsymbol{E} 0^{\prime} * \boldsymbol{L}=46.165
$$

From the calculation of the example, we can get the evaluation grade corresponding to each index. As we can see from Tab. 6 , the user's credit is very low, mainly due to the user's behaviour and less interaction with friends.

We chose Weibo as the source of data, and combining basic information with behavioural data, we can calculate the user's credit score, finally get the corresponding credit rating. The case analysis shows that the behavioural data occupies a large proportion in the credit evaluation process. From the user's behaviour on the Weibo platform, we will learn the degree of user's activity, friends, interests, emotional expression and so on. The purpose of this paper is providing a method for the evaluation of personal credit in the context of big data, in order to help the banks or other financial institutions to verify user's credit from the behavioural data. In the absence of debit record or personal information, the user's credit can also be evaluated by behavioural data. And the data is crawled from Weibo,

\begin{tabular}{|c|c|c|c|}
\hline \multicolumn{4}{|c|}{$\begin{array}{cc}\text { ID: FreshBoy } & \text { Credit Score: } 46.165 \\
\text { The grade of evaluation: Very Poor }\end{array}$} \\
\hline The first index & Grade & The secondary index & Grade \\
\hline \multirow{2}{*}{ A } & \multirow{2}{*}{ Very Good } & A1 & General \\
\hline & & A2 & Very Good \\
\hline \multirow{5}{*}{ B } & \multirow{5}{*}{ Poor } & $\mathrm{B} 1$ & Good \\
\hline & & B2 & Very Good \\
\hline & & B3 & Poor \\
\hline & & B4 & General \\
\hline & & B5 & Poor \\
\hline \multirow{2}{*}{$\mathrm{C}$} & \multirow{2}{*}{ Very Poor } & $\mathrm{C} 1$ & Good \\
\hline & & $\mathrm{C} 2$ & Very Poor \\
\hline
\end{tabular}
which is really valid and effective. The behavioural data is not easy to fake, which is different from other researchers' data from cooperative banks or third-party organizations.

Table 6 The result of FreshBoy's credit evaluation

\section{CONCLUSIONS}

In this paper, we focused on the Weibo social data especially behavioural data, which could be used as the original data to evaluate the user's credit. We proposed a unique credit evaluation index system and proved that behavioural data was reasonable. Scholars should pay more attention to behavioural data in credit scoring studies. This paper proved that AHP and fuzzy comprehensive evaluation method were feasible in the process of credit scoring, and it was very important to establish an effective credit evaluation index system in this process. We constructed an index system based on user's daily behaviour, which proved to be reasonable. In the context of the increasing number of Internet users, the credit evaluation method proposed in this paper is expected to be helpful to online credit evaluation.

In future works, we will first verify the results of the method and compare the results with a standard to achieve the consistency, such as financial data or financial data; second, we will try to use machine learning methods to evaluate the credit of Weibo users in order to reduce subjectivity.

\section{Acknowledgment}

The work was supported by the Natural Science Foundation of China under Grant No. 61502414 and the Zhejiang Provincial Natural Science Foundation of China under Grant No. LQ14F010006.

\section{REFERENCES}

[1] Wang, G., Hao, J., Ma, J., \& Jiang, H. (2011). A comparative assessment of ensemble learning for credit scoring. Expert Systems with Applications, 38(1), 223-230. https://doi.org/10.1016/j.eswa.2010.06.048

[2] Ju, Y. \& Sohn S. Y. (2017). Technology Credit Scoring Based on a Quantification Method. Sustainability, 9(6), 1057. https://doi.org/10.3390/su9061057

[3] Finlay, S. (2011). Multiple classifier architectures and their application to credit risk assessment. European Journal of Operational Research, 210(2), 368-378. https://doi.org/10.1016/j.ejor.2010.09.029

[4] Kruppa, J., Schwarz, A., Arminger, G., \& Ziegler, A. (2013). Consumer credit risk: individual probability estimates using machine learning. Expert Systems with Applications, 40(13), 5125-5131. https://doi.org/10.1016/j.eswa.2013.03.019

[5] Wang, H. Y., Liao, C., \& Kao, C. H. (2013). A credit assessment mechanism for wireless telecommunication debt collection: an empirical study. Information Systems and Ebusiness Management, 11(3), 357-375. https://doi.org/10.1007/s10257-012-0192-x

[6] Qiang, X., Rui-Chun, H., \& Wie, Z. (2015). Research on the e-commerce credit scoring model using the Gaussian density function. Journal of Information Processing Systems, 11(2), 173-183.

[7] Guo, G., Zhu, F., Chen, E., Liu, Q., Wu, L., \& Guan, C. (2016). From footprint to evidence: an exploratory study of mining social data for credit scoring. ACM Transactions on the Web, 10(4), 22. https://doi.org/10.1145/2996465

[8] Zhang, Y., Jia, H., Diao, Y., Hai, M., \& Li, H. (2016). Research on credit scoring by fusing social media information in online peer-to-peer lending. Procedia Computer Science, 91, 168-174. https://doi.org/10.1016/j.procs.2016.07.055 
[9] Ignatius, J., Hatami-Marbini, A., Rahman, A., Dhamotharan, L., \& Khoshnevis, P. (2016). A fuzzy decision support system for credit scoring. Neural Computing and Applications, 1-17.

[10] Li, C. T., Shan, M. K., Jheng, S. H., \& Chou, K. C. (2016). Exploiting concept drift to predict popularity of social multimedia in microblogs. Information Sciences, 339(C), 310-331. https://doi.org/10.1016/i.ins.2016.01.009

[11] Westerman, D., Spence, P. R., \& Heide, B. V. D. (2014). Social media as information source: recency of updates and credibility of information. Journal of Computer-Mediated Communication, 19(2), 171-183. https://doi.org/10.1111/jcc4.12041

[12] Fei, W., Gu, J., Yang, Y., \& Zhou, Z. (2015). Credit risk evaluation based on social media. Environmental Research, 55, 725-731.

[13] Danyllo, W. A., Alisson, V. B., Alexandre, N. D., Moacir, L. M. J., Jansepetrus, B. P., \& Oliveira, R. F. (2013). Identifying Relevant Users and Groups in the Context of Credit Analysis Based on Data from Twitter. International Conference on Cloud \& Green Computing. IEEE Computer Society, 2013, 587-592. https://doi.org/10.1109/CGC.2013.102

[14] Lee, T. S., Chiu, C. C., Lu, C. J., \& Chen, I. F. (2002). Credit scoring using the hybrid neural discriminant technique. Expert Systems with Applications, 23(3), 245-254. https://doi.org/10.1016/S0957-4174(02)00044-1

[15] Gu, W., Basu, M., Chao, Z., \& Wei, L. (2017). A unified framework for credit evaluation for internet finance companies: multi-criteria analysis through AHP and DEA. International Journal of Information Technology \& Decision Making, 16(03), 597-624. https://doi.org/10.1142/S0219622017500134

[16] Bekhet, H. A. \& Eletter, S. F. K. (2014). Credit risk assessment model for Jordanian commercial banks: neural scoring approach. Review of Development Finance, 4(1), 2028. https://doi.org/10.1016/j.rdf.2014.03.002

[17] Zemouri, R., Gouriveau, R., \& Ciprian, P. (2010). Improving the prediction accuracy of recurrent neural network by a PID controller. International Journal of Systems Applications Engineering \& Development, 4(2), 19-34.

[18] Oreski, S. (2014) Hybrid Techniques of Combinatorial Optimization with Application to Retail Credit Risk Assessment. Artificial Intelligence \& Applications, 1(1), 2143. https://doi.org/10.15764/AIA.2014.01002

[19] Keun, Y. T., Won, K. D., Beom, C. S., Ein, O., Soo, P. J., \& Jose, C. (2016). Simple scoring system and artificial neural network for knee osteoarthritis risk prediction: a crosssectional study. PLOS ONE, 11(2), e0148724. https://doi.org/10.1371/journal.pone.0148724

[20] Kammoun, A. K. (2016). Credit Scoring Models for a Tunisian Microfinance Institution: Comparison between Artificial Neural Network and Logistic Regression. Review of Economics \& Finance, 61-78.

[21] Tsai, C. F. \& Hung, C. (2014). Modeling credit scoring using neural network ensembles. Kybernetes, 43(7), 1114-1123. https://doi.org/10.1108/K-01-2014-0016

[22] Bellotti, T. \& Crook, J. (2009). Support vector machines for credit scoring and discovery of significant features. Expert Systems with Applications, 36(2), 3302-3308. https://doi.org/10.1016/j.eswa.2008.01.005

[23] Siami, M., Gholamian, M. R., \& Basiri, J. (2013). An application of locally linear model tree algorithm with combination of feature selection in credit scoring. International Journal of Systems Science, 45(10), 1-10.

[24] Wang, G. \& Ma, J. (2012). A hybrid ensemble approach for enterprise credit risk assessment based on support vector machine. Expert Systems with Applications, 39(5), 53255331. https://doi.org/10.1016/j.eswa.2011.11.003

[25] Blaivas, M. \& Adhikari, S. (2010). Modelling small-business credit scoring by using logistic regression, neural networks and decision trees. Intelligent Systems in Accounting Finance \& Management, 13(3), 133-150.

[26] Chang, Y. C., Chang, K. H., Chu, H. H., \& Tong, L. I. (2016). Establishing decision tree-based short-term default credit risk assessment models. Communications in Statistics. 45(23), 6803-6815. https://doi.org/10.1080/03610926.2014.968730

[27] Bach, M. P., Zoroja, J., \& Jaković, B. (2017).Selection of Variables for Credit Risk Data Mining Models: Preliminary research. Jubilee International Convention on Information \& Communication Technology Electronics \& Microelectronics, 2017, 1599-1604. https://doi.org/10.23919/MIPRO.2017.7973635

[28] Oriol, A., Raffaele, M., \& Marcos, A. R. (2017). Credit Concession through credit scoring: Analysis and application proposal. Intangible Capital, 13(1), 51. https://doi.org/10.3926/ic.903

[29] Nadali, A., Pourdarab, S., \& Nosratabadi, H. E. (2012). Class Labeling of Bank Credit's Customers Using AHP and SAW for Credit Scoring with Data Mining Algorithms. International Journal of Computer Theory \& Engineering, 4, 401-404. https://doi.org/10.7763/IJCTE.2012.V4.492

[30] Ferreira, F. A. F., Santos, S. P., \& Dias, V. M. C. (2014). An AHP-based approach to credit risk evaluation of mortgage loans. International Journal of Strategic Property Management, 18(1), 38-55. https://doi.org/10.3846/1648715X.2013.863812

[31] Chowdhury, S. \& Roy, B. C. (2016). Rating micro finance institutions operating in India: an application of fuzzy analytical hierarchical process (FAHP). Economic Affairs, 61(1), 107-118. https://doi.org/10.5958/0976-4666.2016.00015.2

[32] Li, Y. (2016). Study on the Personal Credit Risk Evaluation based on Improved Fuzzy AHP Comprehensive Evaluation Method. International Conference on Machinery, Materials, Environment, Biotechnology and Computer, 72-76. https://doi.org/10.2991/mmebc-16.2016.15

[33] Hooman, A., Marthandan, G., Yusoff, W. F. W., Omid, M., \& Karamizadeh, S. (2016). Statistical and data mining methods in credit scoring. The Journal of Developing Areas, 50(5), 371-381. https://doi.org/10.1353/jda.2016.0057

[34] Guo, G., Zhu, F., Chen, E., Wu, L., Liu, Q., \& Liu, Y., et al. (2016). Personal Credit Profiling via Latent User Behaviour Dimensions on Social Media. The 20 $0^{\text {th }}$ Pacific-Asia Conference on Advances in Knowledge Discovery and Data Mining, 9652, 130-142.

[35] Emekter, R., Tu, Y., Jirasakuldech, B., \& Lu, M. (2015). Evaluating credit risk and loan performance in online peerto-peer (p2p) lending. Applied Economics, 47(1), 54-70. https://doi.org/10.1080/00036846.2014.962222

[36] Freedman, S. \& Jin, G. Z. (2017). The information value of online social networks: lessons from peer-to-peer lending. International Journal of Industrial Organization, 51, 185222. https://doi.org/10.1016/j.ijindorg.2016.09.002

[37] Ahmad, M. A. \& Srivastava, J. (2014). Behavioural data mining and network analysis in massive online games. ACM International Conference on Web Search and Data Mining, 673-674. https://doi.org/10.1145/2556195.2556196

[38] Fei, W., Gu, J., Yang, Y., \& Zhou, Z. (2015). Credit risk evaluation based on social media. Environmental Research, $55,725-731$

[39] Lee, R., Wakamiya, S., \& Sumiya, K. (2013). Urban area characterization based on crowd behavioural lifelogs over twitter. Personal and Ubiquitous Computing, 17(4), 605620 https://doi.org/10.1007/s00779-012-0510-9

[40] Yue, K., Wu, H., Fu, X., Xu, J., Yin, Z., \& Liu, W. (2016). A data-intensive approach for discovering user similarities in social behavioural interactions based on the Bayesian network. Neurocomputing, 219(C), 364-375. 
[41] Harari, G. M., Lane, N. D., Wang, R., Crosier, B. S., Campbell, A. T., \& Gosling, S. D. (2016).Using smartphones to collect behavioural data in psychological science: opportunities, practical considerations, and challenges. Perspect Psychol Sci, 11(6), 838-854.

https://doi.org/10.1177/1745691616650285

Contact information:

Jia YU, MSc.

School of Information,

Zhejiang University of Finance and Economics,

Hangzhou 310018, China

E-mail:1292575143@qq.com

Jianrong YAO, Prof., PhD

Corresponding author

School of Information,

Zhejiang University of Finance and Economics,

Hangzhou 310018, China

E-mail: y6310@163.com

Yuangao CHEN, Prof., PhD

School of Information,

Zhejiang University of Finance and Economics,

Hangzhou 310018, China

E-mail: chenyg@zufe.edu.cn 